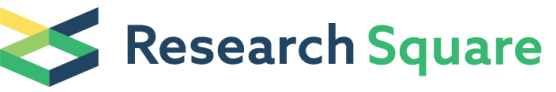 \\ Preprints are preliminary reports that have not undergone peer review. \\ They should not be considered conclusive, used to inform clinical practice, \\ or referenced by the media as validated information.
}

\section{Validation and Optimal Cut-Off Score of the WHO-5 as a Screening Tool for Depression among Young Adults in Malaysia}

\section{Kah-Yue Low}

Universiti Tunku Abdul Rahman

Kai-Shuen Pheh

Universiti Tunku Abdul Rahman

Chee-Seng Tan ( $\nabla$ cstan@outlook.my )

Universiti Tunku Abdul Rahman https://orcid.org/0000-0003-2474-6942

\section{Research Article}

Keywords: confirmatory factor analysis, optimal cut-off, reliability, validity, World Health Organization Well-being Index, WHO-5

Posted Date: April 26th, 2021

DOl: https://doi.org/10.21203/rs.3.rs-445899/v1

License: (c) (i) This work is licensed under a Creative Commons Attribution 4.0 International License. Read Full License

Version of Record: A version of this preprint was published at Current Psychology on August 6th, 2021. See the published version at https://doi.org/10.1007/s12144-021-02152-1. 


\section{Abstract}

As depression has become a major disease burden in Malaysia, an easy-to-use tool with good psychometric is urgently needed to facilitate the screening process. The current study investigated the psychometric qualities of the 5-item World Health Organization Well-being Index (WHO-5) and the optimal cut-off point for depression screening in the Malaysian context. A total of 610 undergraduate students answered an online survey consisting of the English version of the WHO-5 and Patient Health Questionnaire-9 (PHQ-9). Confirmatory factor analysis supported the single-factor model. The WHO-5 also demonstrated good reliability and concurrent validity. Moreover, receiver operating characteristic analysis indicated that $\leq 13$ was the optimal threshold with acceptable sensitivity and specificity. The results support the usability of the WHO-5 to screen for depression among young adults in Malaysia. Moreover, the findings are also consistent with the literature highlighting the potential of the WHO- 5 as a cross-cultural tool for depression screening.

\section{Introduction}

Depression has become a serious public health crisis globally (Herrman et al., 2019). In Malaysia, depression has affected $2.3 \%$ of the adult population and has become the major cause of disease burden (Institute for Public Health, 2020). Therefore, a psychometric sound screening tool is urgently needed for depression research and intervention. The World Health Organization Well-being Index (WHO-5; World Health Organization, 1988) is a measure of subjective well-being and has also been widely used for depression screening (Topp et al., 2015). Although the WHO-5 has been validated in different countries, no studies to date are found in Malaysia. We investigated the suitability of the WHO-5 as a brief depression screening tool in the Malaysian context by testing its factorial structure, validity, reliability, and the optimal cut-off point.

\section{Method}

\section{Design, Participants, and Procedures}

Cross-sectional design and convenience sampling were employed to recruit 615 undergraduate students. Five participants who answered less than $50 \%$ of the items were excluded. Among the 610 respondents $\left(M_{\mathrm{age}}=21.806, S D=2.112\right.$; range $=18$ to 35$), 76,9 \%$ were female. Most of them (84.9\%) were Chinese, followed by Malays (7.4\%), Indians (6.6\%), and other ethnicities (1.2\%). Respondents were students from different years of study, including Year 1 (19.0\%), Year 2 (33.6\%), Year $3(34.9 \%)$, Year 4 and above $(12.3 \%)$, and one as unidentified. Data were collected through social media (e.g., Facebook) from January to March 2021. Ethical approval was obtained from the university (ref. no: [masked for review]). Data were analyzed using JASP.

\section{Measurements}


As English is the medium of instruction in most of the universities in Malaysia, the study employed the original English version of the following scales.

\section{World Health Organization Well-being Index (WHO-5; WHO, 1988)}

WHO- 5 is a self-report five-item scale that measures people's current mental well-being in the past two weeks. Items are rated on a 6-point Likert scale (0: At no time, 5: All of the time). Higher scores indicate better mental well-being.

\section{Patient Health Questionnaire-9 (PHQ-9; Kroenke et al., 2001)}

PHQ-9 is a 9-item measure for the severity of depressive symptoms. Items are rated on a 4-point Likert scale (0: not at all; 3: nearly every day). The PHQ-9 showed a sensitivity of .87 and specificity of .82 in the Malaysian context (Sherina et al., 2012). In this study, PHQ-9 yielded a good internal consistency (Cronbach's alpha $[\nabla]=.869$ ) and a score of $\geq 10$ indicated a depressive episode

\section{Analytical Approach}

A good fit model in confirmatory factor analysis (CFA) possesses a value $\geq .95$ in Comparative fit index (CFI), Tucker-Lewis index (TLI), and goodness of fit (GFI) value and value $<.08$ in root-mean-square error of approximation (RMSEA) and standardized root-mean-square residual (SRMR) (Hu \& Bentler, 1999).

Reliability was examined using $\Downarrow$ coefficient, while the concurrent validity of the WHO- 5 was examined by correlating with the scores of PHQ-9 using Pearson's correlation. Moreover, receiver operating characteristic (ROC) analysis was conducted against PHQ-9 scores to examine the optimal cut-off point for WHO-5. Sensitivity, specificity, positive predictive value (PPV), and negative predictive value (NPV) were calculated to examine the diagnostic accuracy for WHO-5.

\section{Results}

\section{Confirmatory Factor Analysis (CFA)}

The one-factor model showed good fit: $\chi^{2}(5)=36.593, p<.001, \mathrm{CFI}=.982, \mathrm{TLI}=.963, \mathrm{GFI}=.977$, RMSEA $=.102$, and SRMR $=.023$. As RMSEA $>.08$, we referred to modification indices and added an error covariance between items 1 and 4 . The modified model showed excellent fit: $\chi^{2}(5)=11.463, p=.022$, CFI $=.996, \mathrm{TLI}=.989, \mathrm{GFI}=.993, \mathrm{RMSEA}=.055$, and SRMR $=.014$, All (standardized) factor loadings were statistically significant and greater than .90 .

\section{Reliability and Validity}

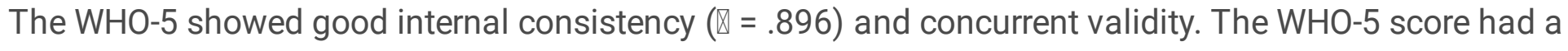
negative correlation with the PHQ-9 score, $r(608)=-.558, p<.001$.

\section{The Optimal Cut-Off for the WHO-5}


Under the cutoff of $12.5 /<13$, the area under the ROC curve was .780 , sensitivity $=.779$ and specificity $=$ .672. The PPV and NPV of the WHO-5 was .670 and .753, respectively.

\section{Discussion}

The present study examined the application of the WHO-5 as a screening tool for depression among Malaysian university students. Our results provide empirical evidence to the usability of the WHO-5.

Consistent with past findings from university students (Ghazisaeedi et al., 2021) and people with medical conditions (Cichoń et al., 2020; Dadfar et al., 2018; Eser et al., 2019), the CFA results support the singlefactor model. Adding error covariance between items 1 (assessing general mood; "I have felt cheerful in good spirits") and 4 (assessing sleep quality; "I woke up feeling fresh and rested") improved the model fit. This could be due to a general mood associated with sleep quality in our sample.

The WHO-5 also showed good reliability and concurrent validity in the present study. Our finding is consistent with those studies conducted with clinical and community samples (e.g., Halliday et al., 2017; Omani-Samani et al., 2019; Perera et al., 2020).

The present study is the first to suggest the cut-off value of WHO-5 in the Malaysian context. Consistent with past studies (e.g., Christensen et al., 2015; Ghazisaeedi et al., 2021; Halliday et al., 2017), the WHO-5 shows acceptable sensitivity $(78 \%)$ and specificity $(67 \%)$ for the optimal $(12.5 / \leq 13)$ cut-off value. The findings highlight the usefulness of the WHO-5 across cultural contexts.

It is noteworthy that the relatively low specificity may lead to false-positive cases. Nevertheless, it is acceptable because people who reported low levels of well-being may suffer from other forms of mental disorders (e.g., anxiety disorders, adjustment disorder) and a follow-up visit to mental health professionals is typically harmless. Importantly, the NPV (0.75) is good, indicating the WHO-5 yielded few false-negative results that may result in unattended mental health problems. Moreover, as Malaysia is a multi-language country, it is recommended to translate the scale into local languages (e.g., Bahasa Malaysia).

\section{Conclusion}

The WHO-5 is a promising rapid mental health screening instrument to detect probable depression among university students.

\section{Declarations}

Funding: The authors did not receive support from any organization for the submitted work.

Conflict of interest: The authors have no conflicts of interest to declare that are relevant to the content of this article. 
Ethical approval: All procedures followed were in accordance with the ethical standards of the responsible committee on human experimentation (institutional and national) and with the Helsinki Declaration of 1975, as revised in 2000 (5). Following the practice of the university, approval was obtained from a group of examiners consisted of the first author and two external examiners.

Consent to participate: Informed consent was obtained from all individual participants included in the study.

Data availability: The datasets generated during and/or analyzed during the current study are available from the corresponding author on reasonable request.

Author contributions: All authors contributed to the study conception and design. Material preparation, data collection and analysis were performed by all authors. The first draft of the manuscript was written by Kah-Yue Low and Kai-Shuen Pheh, and Chee-Seng Tan commented on previous versions of the manuscript. All authors read and approved the final manuscript.

\section{References}

Christensen, K. S., Haugen, W., Sirpal, M. K., \& Haavet, O. R. (2015). Diagnosis of depressed young people -criterion validity of WHO-5 and HSCL-6 in Denmark and Norway. Family practice, 32(3), 359-363. https://doi.org/10.1093/fampra/cmv011

Cichoń, E., Kiejna, A., Kokoszka, A., Gondek, T., Rajba, B., Lloyd, C. E., \& Sartorius, N. (2020). Validation of the Polish version of WHO-5 as a screening instrument for depression in adults with diabetes. Diabetes Research and Clinical Practice, 159, 107970. https://doi.org/10.1016/j.diabres.2019.107970

Dadfar, M., Momeni Safarabad, N., Asgharnejad Farid, A. A., Nemati Shirzy, M., \& Ghazie pour Abarghouie, F. (2018). Reliability, validity, and factorial structure of the World Health Organization-5 Well-Being Index (WHO-5) in Iranian psychiatric outpatients. Trends in Psychiatry and Psychotherapy, 40(2), 79-84. https://doi.org/10.1590/2237-6089-2017-0044

Eser, E., Çevik, C., Baydur, H., Güneş, S., Esgin, T. A., Öztekin, Ç. S., Eker, E., Gümüşsoy, U., Eser, G. B., \& Özyurt, B. (2019). Reliability and validity of the Turkish version of the WHO-5 in adults and older adults for its use in primary care settings. Primary Health Care Research \& Development, 20. https://doi.org/10.1017/S1463423619000343

Ghazisaeedi, M., Mahmoodi, H., Arpaci, I., Mehrdar, S., \& Barzegari, S. (2021). Validity, reliability, and optimal cut-off scores of the WHO-5, PHQ-9, and PHQ-2 to screen depression among university students in Iran. International Journal of Mental Health and Addiction. https://doi.org/10.1007/s11469-021-004835

Halliday, J. A., Hendrieckx, C., Busija, L., Browne, J. L., Nefs, G., Pouwer, F., \& Speight, J. (2017). Validation of the WHO-5 as a first-step screening instrument for depression in adults with diabetes: Results from 
Diabetes MILES - Australia. Diabetes Research and Clinical Practice, 132, 27-35.

https://doi.org/10.1016/j.diabres.2017.07.005

Herrman, H., Kieling, C., McGorry, P., Horton, R., Sargent, J., \& Patel, V. (2019). Reducing the global burden of depression: A Lancet-World Psychiatric Association Commission. The Lancet, 393(10189), e42-e43. https://doi.org/10.1016/S0140-6736(18)32408-5

Hu, L. T., \& Bentler, P. M. (1999). Cutoff criteria for fit indexes in covariance structure analysis: Conventional criteria versus new alternatives. Structural Equation Modeling: A Multidisciplinary Journal, 6(1), 1-55. https://doi.org/10.1080/10705519909540118

Kroenke, K., Spitzer, R. L., \& Williams, J. B. (2001). The PHQ-9: Validity of a brief depression severity measure. Journal of general internal medicine, 16(9), 606-613. https://doi.org/10.1046/j.15251497.2001.016009606.x

Omani-Samani, R., Maroufizadeh, S., Almasi-Hashiani, A., Sepidarkish, M., \& Amini, P. (2019). The WHO-5 Well-Being Index: A validation study in people with infertility. Iranian Journal of Public Health, 48(11), 2058-2064.

Perera, B. P. R., Jayasuriya, R., Caldera, A., \& Wickremasinghe, A. R. (2020). Assessing mental well-being in a Sinhala speaking Sri Lankan population: Validation of the WHO-5 Well-Being Index. Health and Quality of Life Outcomes, 18(1), 305. https://doi.org/10.1186/s12955-020-01532-8

Topp, C. W., Østergaard, S. D., Søndergaard, S., \& Bech, P. (2015). The WHO-5 Well-Being Index: A systematic review of the literature. Psychotherapy and Psychosomatics, 84(3), 167-176.

https://doi.org/10.1159/000376585 